\title{
Does HPV play a role in the etiopathogenesis of ameloblastoma? An immunohistochemical, in situ hybridization and polymerase chain reaction study of 18 cases using laser capture microdissection
}

\author{
Mario Migaldi ${ }^{1}$, Monica Pecorari ${ }^{2}$, Giulio Rossi ${ }^{1}$, Antonio Maiorana ${ }^{1}$, Stefania Bettelli ${ }^{1}$, \\ Maria G Tamassia ${ }^{2}$, Carmela De Gaetani ${ }^{1}$, Pietro Leocata ${ }^{3}$ and Marinella Portolani ${ }^{2}$ \\ ${ }^{1}$ Department of Pathologic Anatomy and Legal Medicine, Section of Pathology; ${ }^{2}$ Department of Medical \\ Laboratory, University of Modena and Reggio Emilia, Modena, Italy and ${ }^{3}$ Department of Experimental \\ Medicine, University of L'Aquila, L'Aquila, Italy
}

\begin{abstract}
Ameloblastomas are epithelial tumors of odontogenic origin, biologically characterized by local recurrence. Among different etiologic factors, HPV infection has been recently postulated to be somehow involved in ameloblastoma etiopathogenesis. To address this issue, we studied 18 ameloblastomas by means of immunohistochemistry, in situ hybridization (conventional and amplified), polymerase chain reaction and nested-polymerase chain reaction analyses using laser capture microdissection in order to detect the occurrence of HPV in this setting. No evidence of HPV infection was detected by morphological examination, immunohistochemistry, in situ hybridization and conventional polymerase chain reaction, while nestedpolymerase chain reaction showed a weak positive band in two cases. However, the subsequent restriction enzyme analysis carried out from the nested-polymerase chain reaction amplification products of these two samples excluded the presence of HPV subtypes 16, 18, 31, 33, 35, 52, and 58. The search for HPV 6 and 11 in the same specimens was also negative. In conclusion, our data do not support an etiopathogenetic evidence for HPV in ameloblastoma.
\end{abstract}

Modern Pathology (2005) 18, 283-289, advance online publication, 23 July 2004; doi:10.1038/modpathol.3800241

Keywords: ameloblastoma; HPV; in situ hybridization; immunohistochemistry; PCR; laser microdissection

Ameloblastoma is the most common odontogenic neoplasm, accounting for approximately $1 \%$ of all oral tumors ${ }^{1}$ and usually affects young adults in the fourth-fifth decades of life, causing local discomfort. $^{2}$ It is characterized by a benign clinical behavior, possibly leading to local recurrences but distant metastases from ameloblastoma are exceedingly rare. ${ }^{3,4}$ The tumor appears as a true odontogenic lesion, although an extraosseous peripheral localization has been described. ${ }^{5}$ At histology, ameloblastoma may display a protean appearance giving rise to several growth patterns, such as

Correspondence: Dr M Migaldi, MD, PhD, Sezione di Anatomia Patologica, Università degli Studi di Modena e Reggio Emilia, Policlinico, Via del Pozzo 71, 41100 Modena, Italy.

E-mail: migaldi@unimo.it

Received 21 May 2004; revised and accepted 25 June 2004; published online 23 July 2004 follicular, plexiform, acanthomatous, basaloid, granular and desmoplastic. ${ }^{1,3}$ The pathogenesis of such tumors is still unclear. In the last decade, a clearcut association has been demonstrated between HPV infection and the development of neoplastic lesions from the squamous epithelium lining the oral cavity. ${ }^{6-8}$ On this basis, some authors have hypothesized that HPV might play a key role also in the pathogenesis of ameloblastoma. Nevertheless, the results so far reported in the literature are quite controversial and not conclusive. HPV was first detected in ameloblastoma by $\mathrm{Kahn}^{9}$ using an immunohistochemical approach. Subsequently, only a few other works were able to detect HPVDNA either by in situ hybridization ${ }^{10,11}$ or by polymerase chain reaction analysis ${ }^{12,13}$ in peripheral or intraosseous ameloblastomas. Since none of these studies have evidenced viral DNA integration into the tumor cells, it remains to be seen whether 
the demonstration of HPV in such tumors should be actually considered a true infectious event promoting the neoplastic cell growth or merely a biologic bystander related to contamination from surface squamous epithelium in which HPV may be detectable in a silent form. ${ }^{14}$ The present study was undertaken to investigate the occurrence of HPV in a series of 18 ameloblastomas using a comprehensive approach including immunohistochemistry, in situ hybridization and polymerase chain reaction analysis. Of note, to prevent contamination by adjacent surface oral epithelium, we first employed a laser microdissection technique to obtain pure tumor nuclear material to be analyzed by a restriction fragment length polymorphism method on a nestedpolymerase chain reaction product against several HPV subtypes.

\section{Materials and methods}

\section{Cases Selection}

A total of 27 consecutive surgical specimens of ameloblastoma (diagnosed from 1991 to 2001) were retrieved from the computerized files of the Section of Pathology of the University of Modena and Reggio Emilia. All the cases included in this study were initially reviewed by two pathologists (GR, AM) by examination of several hematoxylin and eosin-stained tumor slides (mean, 2.5 slides per tumor; range, 2-8) and a consensus diagnosis was reached in all cases. All specimens were fixed in $10 \%$ neutral formalin and then paraffinembedded. Sections were originally stained with hematoxylin and eosin and periodic acid-Schiff. All the cases undergoing decalcification for the presence of bone were excluded from the study (nine cases). The selection did not require approval by an Institutional Review Board because the samples were coded and the names of patients were not revealed.

\section{Immunohistochemistry}

For immunohistochemistry, 4- $\mu$ m-thick sections were obtained from a tumor representative block. Endogenous peroxidase activity was blocked with $3 \%$ hydrogen peroxidase in methanol for 30 min. A modified streptavidin-biotin-peroxidase technique was employed in an automated immunostainer (NexES, Ventana, Strasbourg, France). A mouse monoclonal anti-HPV antibody (clone K1H8, Dako, Glostrup, Denmark) was used. This antibody reacts with a linear epitope of the major capsid protein of HPV-1, resulting broadly expressed among the different HPV subtypes. Appropriate positive (a cervical condyloma) and negative (no primary antibody added) controls were included in each test.

\section{In Situ Hybridization}

Conventional in situ hybridization was performed using a generic biotinylated probe detecting DNAHPV types 6, 11, 16, 18, 31, 33, 51 (Dako, PathoGene Human Papillomavirus Screening Assay). Briefly, 4$\mu \mathrm{m}$-thick sections were deparaffinized, digested with proteinase $\mathrm{K}\left(0.25 \mathrm{mg} / \mathrm{ml}\right.$ for $7 \mathrm{~min}$ at $\left.37^{\circ} \mathrm{C}\right)$ and rehydrated. Target and probe DNAs were denatured by heating at $95^{\circ} \mathrm{C}$ for $8 \mathrm{~min}$. Hybridization was performed in a humid chamber for $1 \mathrm{~h}$ at $37^{\circ} \mathrm{C}$, followed by stringency wash for $10 \mathrm{~min}$ at $37^{\circ} \mathrm{C}$. Detection of biotinylated probes was accomplished with a streptavidin-alkaline phosphatase complex, visualized after conversion of the substrate (5-bromo-4-chloro-3-indolyl-phosphate and nitroblue tetrazolium) into a localized blue-purple precipitate according to Unger. ${ }^{15}$ In order to increase the sensitivity of conventional in situ hybridization, the GenPoint Kit (K0620 Dako) was also employed using a catalyzed signal amplification method as reported by Birner et al. ${ }^{16}$ This technique can detect rare nucleic acid sequences and is based on peroxidasecatalyzed deposition of biotinyl-tyramide, resulting in high amplification of signals at the hybridization site of biotinylated probes. Negative and positive (a cervical condyloma) controls were included during each test.

\section{Laser Capture Microdissection and Polymerase Chain Reaction Analysis}

In all cases, paraffin-embedded sections including both neoplastic areas and non-neoplastic adjacent mucosa were obtained for the molecular study. Laser capture microdissection was performed on $4-\mu \mathrm{m}$ thick hematoxylin and eosin-stained sections using an Olympus IX-70 Scissor 300 microdissector to obtain a pure component of neoplastic epithelial cells and adjacent non-neoplastic squamous epithelium. Then, polymerase chain reaction analysis was performed on microdissected epithelial cells only.

After incubation in a water bath at $56-60^{\circ} \mathrm{C}$ for $30 \mathrm{~min}$, sections were kept in xylene overnight, then centrifuged at 12000 r.p.m. for $5 \mathrm{~min}$. Cell pellets were air-dried for $90 \mathrm{~min}$. DNA was extracted from each cell pellet using the 'salting-out' method according to Zazzi et al. ${ }^{17}$ Since DNA samples were considered suitable for amplification when the $\beta$ globin gene was detected, all cases proved positive for this gene and were available for amplification. Search for HPV-DNA was carried out using two types of polymerase chain reaction assays. The first employed the MY09 and MY11 consensus primers, that target a $450 \mathrm{bp}$ region in the highly conserved ORF region of the HPV genome as previously reported by Resnick et al. ${ }^{18}$ The second assay was a nested-polymerase chain reaction first employing consensus primers (LCRS and E7AS) targeting a region of about $650 \mathrm{bp}$ from long-control region (LCR) to E7 open-reading frame of the HPV genome 
and, subsequently, internal E6-E7 primers (pU-M and pU-2R) targeting a $250 \mathrm{bp}$ region. The nestedpolymerase chain reaction E6-E7 procedure can detect 0.001 copies of HPV-DNA vs 0.1 copies detected by the polymerase chain reaction MY09MY11 method.

The amplification reaction of both polymerase chain reaction assays was carried out in a $50 \mu \mathrm{l}$ final volume containing $100 \mathrm{ng}$ of DNA, $100 \mu \mathrm{M}$ each of deoxynucleotide triphosphates, $10 \mathrm{pmol}$ of each MY09 and MY11 primer, and $1 \mathrm{U}$ Taq polymerase (Eppendorf, Hamburg, Germany). Samples containing the amplification mix were subjected to 40 amplification cycles, each of them including: $1 \mathrm{~min}$ of denaturation step at $95^{\circ} \mathrm{C}, 1 \mathrm{~min}$ of annealing step at $55^{\circ} \mathrm{C}$, and $1 \mathrm{~min}$ of extension step at $72^{\circ} \mathrm{C}$. An initial denaturation at $95^{\circ} \mathrm{C}$ for $5 \mathrm{~min}$ and a final extension step at $55^{\circ} \mathrm{C}$ for $2 \mathrm{~min}$ and at $72^{\circ} \mathrm{C}$ for 5 min were also included in the polymerase chain reaction protocol. The first part of the amplification program of the nested-polymerase chain reaction assay was carried out as previously described by Noda et al. ${ }^{19}$ Briefly, after an initial denaturation at $96^{\circ} \mathrm{C}$ for $5 \mathrm{~min}$, the amplification mix containing LCRS and E7AS primers, was subjected to 5 cycles (each including: denaturation step at $94^{\circ} \mathrm{C}$ for $1 \mathrm{~min}$, annealing step at $45^{\circ} \mathrm{C}$ for $1 \mathrm{~min}$, and extension step at $72^{\circ} \mathrm{C}$ for $1 \mathrm{~min}$ ), five more cycles (each including 1 min steps at 94,48 and $72^{\circ} \mathrm{C}$ ), then 30 cycles (each including $1 \mathrm{~min}$ steps at 94,55 and $72^{\circ} \mathrm{C}$ ).

Finally, a 10 -min denaturation step at $72^{\circ} \mathrm{C}$ was followed by a $10-\mathrm{min}$ treatment at $4^{\circ} \mathrm{C}$. After the $\mathrm{pU}-\mathrm{M}$ and $\mathrm{pU}-2 \mathrm{R}$ primers addition to the mix, the internal amplification program was the following: denaturation at $96^{\circ} \mathrm{C}$ for $3 \mathrm{~min}, 30$ amplification cycles each including treatments at $94^{\circ} \mathrm{C}$ for $1 \mathrm{~min}$, at $55^{\circ} \mathrm{C}$ for $2 \mathrm{~min}$ and $72^{\circ} \mathrm{C}$ for $2 \mathrm{~min}$. A final treatment was carried out at $55^{\circ} \mathrm{C}$ for $2 \mathrm{~min}$, at $72^{\circ} \mathrm{C}$ for $5 \mathrm{~min}$ and at $4^{\circ} \mathrm{C}$ for $10 \mathrm{~min}$. Aliquots $(5 \mu \mathrm{l})$ of polymerase chain reaction and nested-polymerase chain reaction amplification products were subjected to electrophoresis on $3 \%$ agarose gel followed by ethidium bromide staining. Restriction fragments polymorphism was used for HPV typing. Using appropriate restriction enzymes (Rsa I, Ava II, Sau 3 AI, ACc I), this polymerase chain reaction method can detect HPV genome of several subtypes, including types 16, 18, 31, 33, 35, 52 and 58. Search for HPV DNA 6 and 11 was carried out by polymerase chain reaction assays employing specific primers as elsewhere suggested. ${ }^{20}$

\section{Results}

\section{Clinicopathologic Findings}

The most relevant clinicopathologic features are summarized in Table 1 . In all, 10 patients (56\%) were female and eight (44\%) were male. The patients age ranged from 15 to 87 years (mean, 41 years; median, 29 years). The lower jaw was the most common site of tumor involvement (14 cases; $78 \%$ ), while the tumor affected the upper jaw in the reminder four cases $(22 \%)$. In total, 11 patients underwent radical tumor excision and seven received a partial resection. Local tumor recurrence occurred in seven cases. Follow-up data, ranging from 13 to 130 months (median, 88.5 months), were obtained in each patient. Ameloblastoma-related distant metastases and/or deaths were not recorded.

Histologically, six cases showed the classic follicular growth pattern and six were of plexiform type. Three cases displayed a mixed histotype (two plexiform/acanthomatous and one follicular/

Table 1 Clinicopathologic characteristics of the patients

\begin{tabular}{|c|c|c|c|c|c|c|c|}
\hline Case no. & Sex & Age (years) & Site & Follow-up (months) & Histologic subtype & Primary surgery & Tumor recurrence \\
\hline 1 & $\mathrm{~F}$ & 21 & LJ & AW (24) & $\mathrm{F}$ & $\mathrm{R}$ & No \\
\hline 2 & M & 15 & LJ & AW (107) & $\mathrm{F}$ & $\mathrm{R}$ & No \\
\hline 3 & $\mathrm{~F}$ & 29 & LJ & AW (49) & F-A & $\mathrm{R}$ & No \\
\hline 4 & M & 22 & LJ & AW (90) & $\mathrm{P}$ & $\mathrm{R}$ & No \\
\hline 5 & M & 17 & LJ & AW (42) & $\mathrm{P}$ & NR & Yes \\
\hline 6 & $\mathrm{~F}$ & 58 & LJ & AW (98) & $\mathrm{F}$ & $\mathrm{R}$ & Yes \\
\hline 7 & $\mathrm{M}$ & 66 & LJ & AW (41) & A & NR & Yes \\
\hline 8 & M & 69 & LJ & AW (44) & $\mathrm{F}$ & $\mathrm{R}$ & No \\
\hline 9 & $\mathrm{~F}$ & 87 & LJ & DUC (18) & $\mathrm{F}$ & $\mathrm{R}$ & No \\
\hline 10 & $\mathrm{~F}$ & 70 & UJ & AW (93) & P-A & $\mathrm{R}$ & No \\
\hline 11 & $\mathrm{~F}$ & 58 & LJ & AW (98) & $\mathrm{P}$ & $\mathrm{R}$ & No \\
\hline 12 & $\mathrm{~F}$ & 27 & LJ & AW (112) & $\mathrm{D}$ & NR & Yes \\
\hline 13 & $\mathrm{~F}$ & 29 & LJ & AW (102) & $\mathrm{P}$ & NR & Yes \\
\hline 14 & $\mathrm{M}$ & 82 & UJ & DUC (13) & $\mathrm{P}-\mathrm{A}$ & $\mathrm{R}$ & Yes \\
\hline 15 & $\mathrm{~F}$ & 39 & UJ & AW (109) & A & NR & No \\
\hline 16 & $\mathrm{~F}$ & 16 & UJ & AW (130) & $\mathrm{F}$ & NR & Yes \\
\hline 17 & $\mathrm{M}$ & 18 & LJ & AW (87) & $\mathrm{P}$ & $\mathrm{R}$ & No \\
\hline 18 & M & 22 & LJ & AW (54) & $\mathrm{P}$ & NR & No \\
\hline
\end{tabular}

M, male; F, female; LJ, lower jaw; UJ, upper jaw; AW, alive and well; DUC, died of unrelated cause; R, radical excision; NR, nonradical excision; F, follicular; P, plexiform; A, acantomathous, D, desmoplastic. 

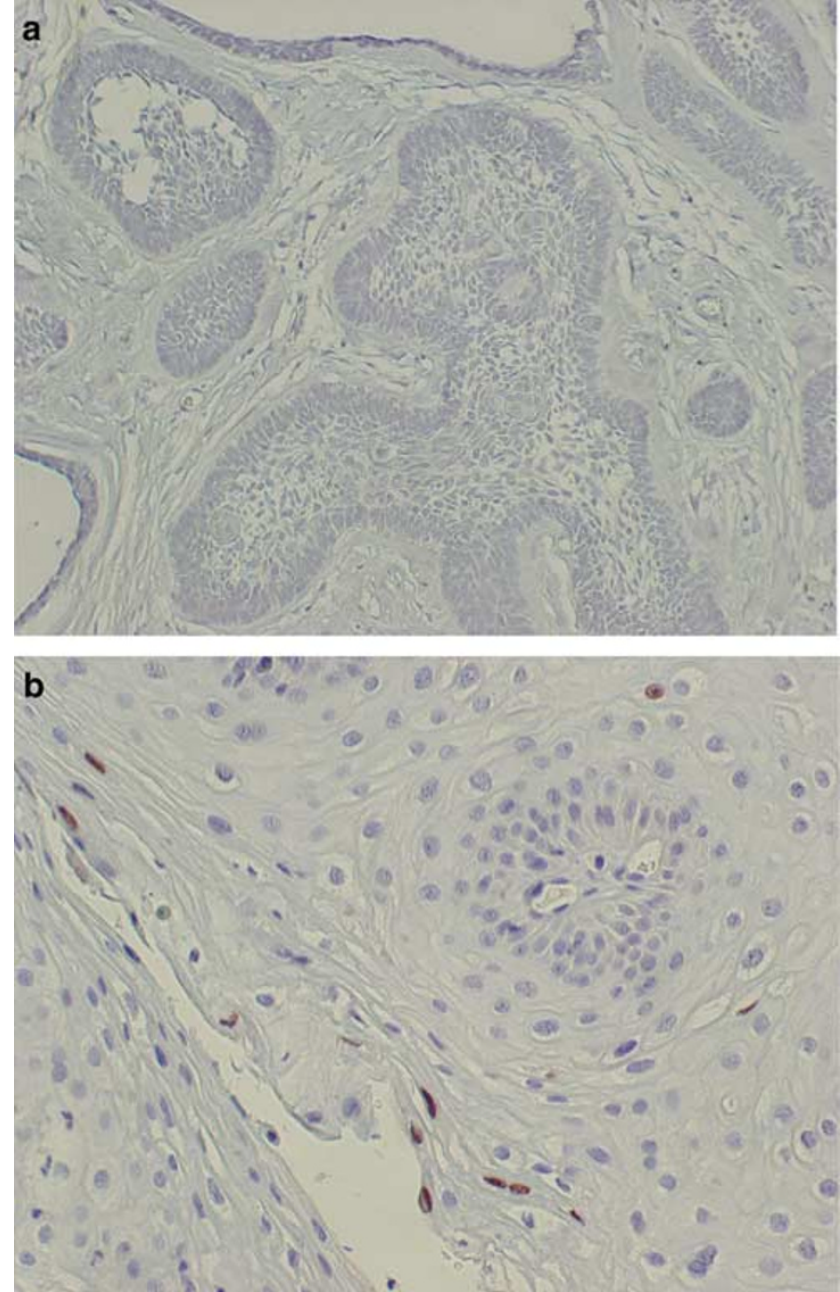

Figure 1 Ameloblastoma is completely unstained with anti-HPV (a, immunohistochemistry, monoclonal anti-HPV clone K1H8, $\times 100$ ), while an appropriate positive control (uterine cervix condyloma) displayed nuclear positivity (b, immunohistochemistry, monoclonal anti-HPV clone K1H8, $\times 200$ ). No evidence of cytopathologic alterations have been found in ameloblastoma, while koilocytosis and multinucleation were evident in the positive control.

acanthomatous), while one case each of acanthomatous-type and desmoplastic-type ameloblastoma were observed. In all cases, we failed to find any evidence of HPV-induced cytological changes, such as koilocytosis, nuclear enlargement with atypia or multinucleation features. Supporting the morphologic impression, we did not observe any reaction against the HPV-capsid antigen by means of immunohistochemistry (Figure 1a and b). Moreover, no immunostaining was found in the non-neoplastic adjacent tissue. Even in situ hybridization analysis (conventional and after catylyzed signal amplification) did not detect any HPV-DNA in neoplastic and non-neoplastic samples (Figure 2a and b). At polymerase chain reaction assay with MY09 and MY11 primers, both laser-microdissected neoplastic and normal tissue samples turned out to be negative
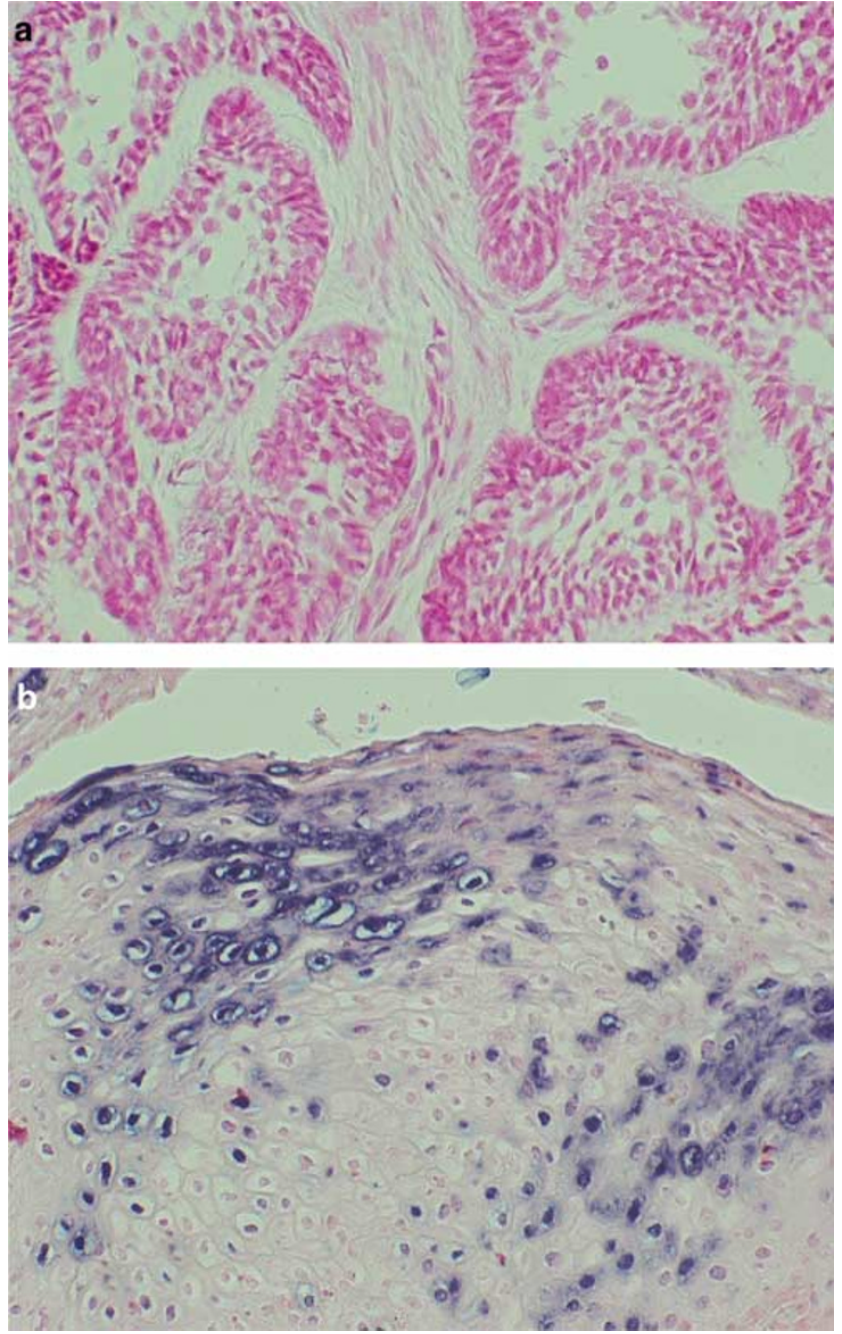

Figure 2 Ameloblastoma did not express any positivity for HPVDNA (a, in situ hybridization, anti-HPV-DNA, $\times 200$ ), while an appropriate positive control (uterine cervix condyloma) displayed nuclear and cytoplasmic positivity (b, in situ hybridization, antiHPV-DNA, $\times 200$ ). As shown in Figure 1, no signs of HPV-related cytopathologic alterations have been found in ameloblastoma, while koilocytosis and multinucleation were evident in the positive control.

for HPV-DNA. When samples were processed by nested-polymerase chain reaction assay using E6 and E7 primers, two tumor tissue samples (cases 3 and 9) and the corresponding specimens of adjacent tissue showed a weak positive band (Figure 3). However, the restriction enzyme analysis carried out on the nested-polymerase chain reaction amplification products from these samples excluded the presence of the HPV subtypes 16, 18, 31, 33, 35, 52, 58. Again, the search for HPV 6 and 11 in the same HPV-DNA samples resulted negative.

\section{Discussion}

Several works have recently suggested that HPV might be somehow implicated in the pathogenesis of 


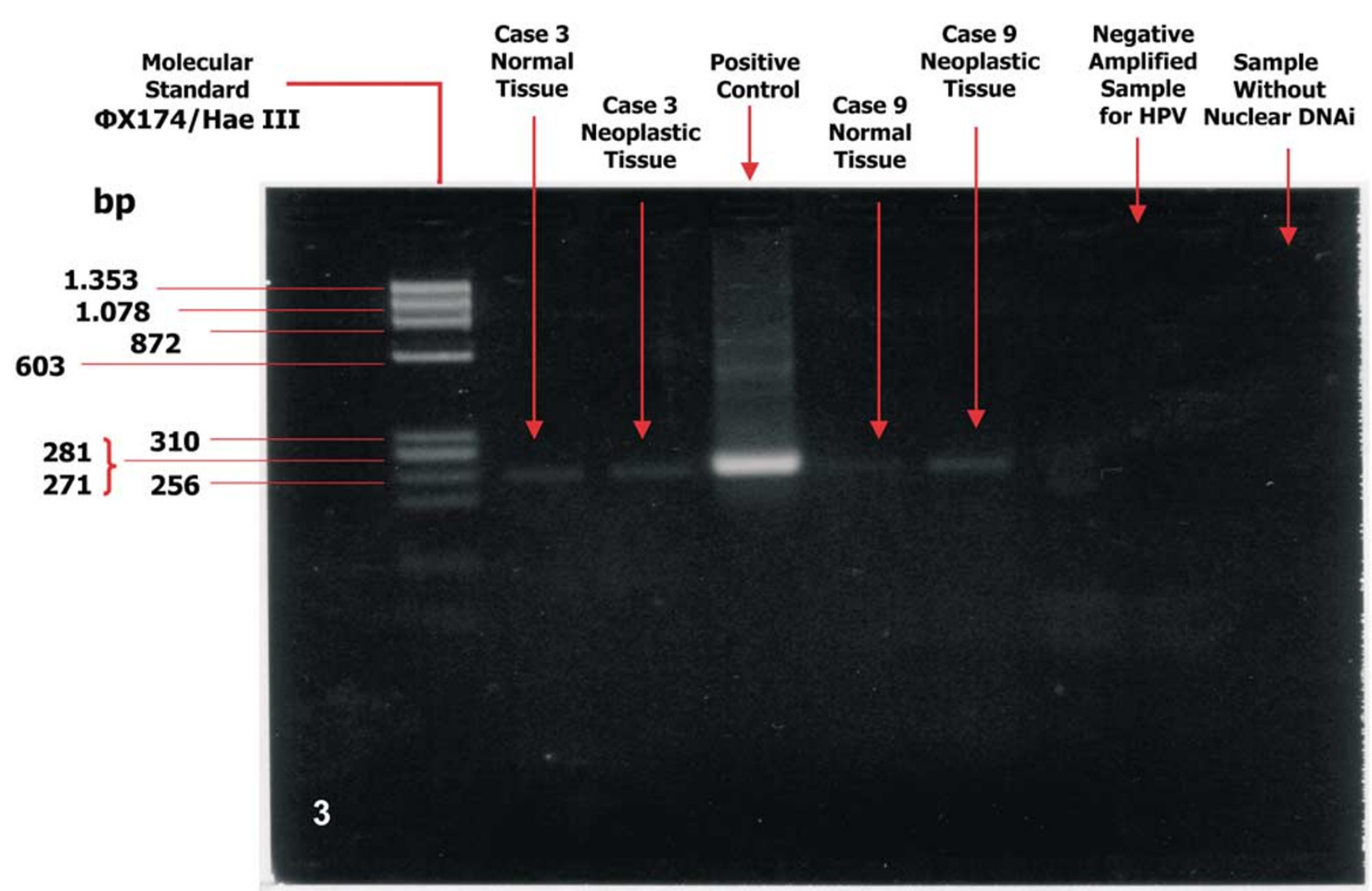

Figure 3 Nested-polymerase chain reaction analysis using E6-E7 primers showed a weak positive band in cases 3 and 9.

ameloblastoma, the most common odontogenic tumor usually associated with a benign biologic behavior. HPV in such tumors was first detected by immunohistochemistry using a polyclonal antibody directed against bovine papillomavirus. ${ }^{9}$ This study showed a nuclear immunoreaction for HPV capsid antigen in three out of 10 ameloblastomas developed in patients younger than 19 years, whereas no positivity was found in adult cases (0 out of 10). ${ }^{9}$ Subsequently, a positivity for HPV-DNA (types 16 and 18) was demonstrated by in situ hybridization in an extraosseus peripheral ameloblastoma arisen in 16-year-old black male, ${ }^{10}$ then suggesting that HPV might be associated, if not directly involved, in promoting tumor cell growth. The positive nuclear reaction was evidenced in peripheral columnar epithelial cells and in a few central stellate reticulum cells. ${ }^{10}$ Analogously, type $18 \mathrm{HPV}$ was detected in a case of intraosseous ameloblastoma by Van Heerden et $a l^{11}$ using radiolabelled in situ hybridization. Since the viral DNA was observed only in a verrucous lesion located in a adjacent cystic area, but not in the tumor epithelial component, this finding was considered to represent a secondary viral infection. ${ }^{11}$ More recently, a polymerase chain reaction-based study evidenced HPVDNA sequences in eight out of $12(67 \%)$ cases of intraosseus ameloblastomas. ${ }^{12}$ In particular, employ- ing L1 consensus primer and specific primers against HPV types 6,11, 16 and 18, seven samples were positive for type $18 \mathrm{HPV}$ and four of them tested positive also for type 6 and 11 . One of the HPV-positive cases did not react for type-specific primers and HPV-DNA was detected only at secondary surgery in three patients. ${ }^{12}$ This fact led the authors to postulate that the detection of HPV-DNA in ameloblastomas might be related to surgical manipulation causing tumor contamination from adjacent surface mucosal epithelium. ${ }^{12}$ Finally, HPV positivity employing a polymerase chain reaction analysis was reported in 20 out of 50 samples of ameloblastoma and in nine out of 50 impacted third molar follicles used as normal control group by Namin et al. ${ }^{13}$ Given that none of the above works demonstrated a real integration of HPV-DNA into the tumor cells of ameloblastoma, the majority of these authors correctly underlined that the presence of HPV-DNA positivity in ameloblastoma likely represented a secondary surgically acquired contamination from the overlying oral mucosa or a secondary event rather than a true infection. ${ }^{11,12}$ It is wellknown that HPV shows a peculiar tropism for squamous epithelium of different mucosal sites, mainly of the oral and anogenital regions where it is deeply implicated in the pathogenesis of squamous cell carcinoma. Several histologic HPV-related 
alterations are easily recognizable in this latter occurrence when HPV integrates and replicates its DNA into the host cells, such as koilocytosis, nuclear enlargement and multinucleation associated with prominent nucleoli. By contrast, we did not observe such morphological modifications either in our cases of ameloblastoma or in the available microphotographs of the aforementioned works. Moreover, ameloblastoma generally arises from the epithelial lining of dentigerous cysts, enamel organ or from the basal layer of the oral mucosa and it is therefore sequestered within the bone and relatively unexposed to HPV. Thus, it is more likely that the viral presence merely represented a biologic bystander without changes related to active infection. ${ }^{14}$ However, we failed to evidence capsid proteins or HPV-DNA when appropriate immunohistochemical marker and sensitive probes by in situ hybridization were applied, respectively. Given that molecular analysis requires a high degree of tumor cells purity, we employed the newly described technique of laser capture microdissection ${ }^{21}$ under microscopic visualization to select a specific cell population and avoid a possible contamination from adjacent oral mucosa. In two of our cases, a weak amplified band was found. The origin of this finding could be likely related to the fact that during the polymerase chain reaction process nonspecific DNA synthesis may occur whenever a primer anneals to an incompletely homologous region of the original nucleic acid. ${ }^{22}$ Nevertheless, polymerase chain reaction and nested-polymerase chain reaction analyses using a restriction fragment length polymorphism method including internal E6-E7 primers resulted negative, thus excluding any presence of HPV-DNA in ameloblastoma.

In conclusion, our study first approached in an organic way the possible etiopathogenic role of HPV in ameloblastoma. The results herein seem to reasonably rule out any implication of HPV in this tumor. Finally, since all patients included in this study were of Caucasian origin, we cannot completely exclude that HPV might be possibly involved at least in a subset of ameloblastomas occurring in subjects from other geographic areas, as commonly happens in other virus-related neoplastic disorders. $^{23}$

\section{Acknowledgement}

This work was funded by a grant of the Ministero dell'Istruzione, dell'Università e della Ricerca (MIUR, Rome).

\section{References}

1 Melrose RJ. Benign epithelial odontogenic tumors. Semin Diagn Pathol 2002;16:271-287.
2 Philipsen HP, Reichart PA, Nikai H, et al. Peripheral ameloblastoma: biological profile based on 160 cases from the literature. Oral Oncol 2001;37:17-27.

3 Regezi JA. Odontogenic cysts, odontogenic tumors, fibroosseous, and giant cell lesions of the jaws. Mod Pathol 2002;15:331-341.

4 Hyvernat P, Ollagnier C, Freidel M, et al. Pulmonary metastasis of an ameloblastoma. Rev Mal Respir 1985; 2:15-18.

5 Anneroth, G, Johansson B. Peripheral ameloblastoma. Int J Oral Surg 1985;14:295-299.

6 Tsuchiya H, Tomita Y, Shirasawa H, et al. Detection of human papillomavirus in head and neck tumors with DNA hybridization and immunohistochemical analysis. Oral Surg Oral Med Oral Pathol 1991;71:721-725.

7 Ostwald C, Muller P, Barten M, et al. Human papillomavirus DNA in oral squamous cell carcinomas and normal mucosa. J Oral Pathol Med 1994;23: 220-225.

8 Mao EJ, Schwartz SM, Daling JR, et al. Human papilloma viruses and p53 mutations in normal premalignant and malignant oral epithelia. Int J Cancer 1996;69:152-158.

9 Kahn MA. Ameloblastoma in young persons: a clinicopathologic analysis and etiologic investigation. Oral Surg Oral Med Oral Pathol 1989;67:706-715.

10 Kahn MA. Demonstration of human papillomavirus DNA in a peripheral ameloblastoma by in situ hybridization. Hum Pathol 1992;23:188-191.

11 Van Heerden WF, van Rensburg EJ, Raubenheimer EJ, et al. Detection of human papillomavirus DNA in an ameloblastoma using the in situ hybridization technique. J Oral Pathol Med 1993;22:109-112.

12 Sand L, Jalouli J, Larsson PA, et al. Presence of human papilloma viruses in intraosseous ameloblastoma. J Oral Maxillofac Surg 2000;58:1129-1134.

13 Namin AK, Azad TM, Eslami B, et al. A study of the relationship between ameloblastoma and human papilloma virus. J Oral Maxillofac Surg 2003;61: 467-470.

14 Eisenberg E. Presence of human papilloma viruses in intraosseous ameloblastoma. J Oral Maxillofac Surg 2000;58:1135-1136.

15 Unger ER. In situ diagnosis of human papillomaviruses. Clin Lab Med 2000;20:289-301.

16 Birner P, Bachtiary B, Dreier B, et al. Signal-amplified colorimetric in situ hybridization for assessment of human papillomavirus infection in cervical lesions. Mod Pathol 2001;14:702-709.

17 Zazzi M, Catucci M, De Milito A, et al. Zidovudine resistance mutations and human immunodeficiency virus type 1 DNA burden: longitudinal evaluation of six patients under treatment. Infection 1996;24: 419-425.

18 Resnick RM, Cornelisen MTE, Wright DK, et al. Detection and typing of human papillomavirus in archival cervical cancer specimens by DNA amplification with consensus primers. J Nat Cancer Inst 1990; 82:1477-1484.

19 Noda T, Sasagawa T, Dong Y, et al. Detection of human papillomavirus (HPV) DNA in archival specimens of benign prostatic hyperplasia and prostatic using a highly sensitive nested PCR method. Urol Res 1998; 26:165-169.

20 Soler C, Allibert P, Chardonnet V, et al. Detection of human papillomavirus types 6, 11, 16 and 18 in mucosal and cutaneous lesions by the multiplex 
polymerase chain reaction. J Virol Methods 1991;35: 143-157.

21 Burgemeister R, Gangnus R, Haar B, et al. High quality RNA retrieved from samples obtained by using LMPC (laser microdissection and pressure catapulting) technology. Pathol Res Pract 2003;199: 431-436.
22 Guatelli JC, Gingeras TR, Richman DD. Nucleic acid amplification in vitro: detection of sequences with low copy numbers and application to diagnosis of human immunodeficiency virus type 1 infection. Clin Microbiol Rev 1989;2:217-226.

23 Dalgleish AG. Viruses and cancer. Br Med Bull 1991; 47:21-46. 